\title{
The grand challenges in functional plant ecology
}

\section{Christian Körner*}

Institute of Botany, University of Basel, Basel, Switzerland

${ }^{*}$ Correspondence: ch.koerner@unibas.ch

The science, this section-journal of Frontiers in Plant Sciences will be covering at great breadth and depth, aims at linking plant responses with the environment. The environmental influences are manifold and include both abiotic and biotic ones. The first include physical and chemical influences, the latter include plant-plant, plant-animal, plant-microbe (incl. virus) interactions. The plant responses considered go from gene to ecosystem scale. Building upon more than a century of functional plant ecology, any attempt at sketching the challenges ahead is inevitably rather subjective, reflecting personal experience, and expertise.

Plant ecology covers both, basic science and oriented (applied) science, the latter under strong influence of the ongoing attempts at understanding impacts of environmental changes, particularly those, commonly subsumed under "global change." The current wave of global change research often tends to lack sound foundation in theory, because functional plant ecology is a relatively young science and the applied questions came up before many of the more basic queries had been answered. On the other hand, the great motivation associated with global change research, will exert a new momentum in exploring the underlying principles of plant responses to the environment. In three sections, I will try to reflect on how this field of science developed, and from there, will distil a few tasks that I would rank as grand challenges. Several references were chosen to emphasize that the insights are rather classics, but their appreciation has not become common sense.

\section{CARBON SINKS DRIVE CARBON SOURCES: SINK ACTIVITY IS DRIVEN BY DEVELOPMENT AND ENVIRONMENTAL LIMITATIONS}

Our current vision of how plants grow and develop, largely roots in the discoveries by Jan Ingenhousz in 1779 and Nicolas Théodoré de Saussure in 1804 of plant gas exchange, namely that plants build their body from $\mathrm{CO}_{2}$ taken up from air. Since those days, plant growth was largely seen in the light of leaf photosynthesis and its abiotic drivers such as photon flux, water availability, and temperature. In 1839 , Justus Liebig added the insight, that it is the availability of mineral nutrients that are responsible for what people had considered "good soil" for millennia, and that the differential availability of these macroand micro-nutrients pose critical limits to growth. Maybe it was because Liebig's discovery came half a century later that the focus remained on carbon. "The air we breath is feeding the plants and thus us" may also be seen as a more appealing view than "dirt is feeding us," and thus, plant growth phenomena are largely seen from a carbon perspective until the very present. Direct environmental impacts on tissue formation and developmental constraints are often neglected.

For instance, quite often, plant growth is driving photosynthesis, rather the other way round. Exceptions are growth in deep shade or under unlimited nutrient supply. Why is this so? Since outside horticulture and intense crop production, nutrient availability is finite, plants always compete for nutrients, not for $\mathrm{CO}_{2}$, although they compete for light to fix $\mathrm{CO}_{2}$. However, light competition has two facets, the capture of $\mathrm{CO}_{2}$, and the suppression of neighbors that are foraging for the same soil nutrients. So, plants invest in foliage far beyond the need to capture light, because these leaves hold nutrients that had been captured from the "open market" and are at disposal for internal re-investment, and because plants are never alone, these leaves reduce the options of neighbors to thrive. Foliage and its quality also have to be viewed in the context of amortization and the risk of getting eaten or infected by pathogens. Evolution selects for reproductive fitness not necessarily associated with big body mass. Hence, capture of $\mathrm{CO}_{2}$ makes only sense to the extent assimilates can be invested in growth and translate into successful offspring, and growth requires mineral nutrients.

The challenge ahead is to identify and quantify developmental (internal) and environmental constraints to tissue formation, and how tissue activity feeds back on leaf gas exchange. Long known in crop and orchard research (Gifford and Evans, 1981; Wardlaw, 1990; Farrar, 1993), it needs active sinks to channel photosynthates away from $\mathrm{CO}_{2}$ capturing leaves. Evolutionary selection had also arrived at certain life history traits that ensure best plant performance in an ever-changing environment (Mooney, 1972). This means, plants pass through ontogenetic and seasonal life stages during which resource dependency and stress tolerance greatly differ. These life stages (e.g., germinating, leaf unfolding, flowering, seed maturation) are under internal (hormonal, genetic) control, which in turn track signals from the environment such as certain climatic histories (past chilling or drought events), photoperiod (astronomic calendar), or competitive status (e.g., red/ far-red or allochemical signals).

Developmental ecology needs to become a frontier topic of plant ecology, despite the lack of "neat machines" to be employed and the often laborious observational work. Gene-ecology will play a key role in the development of this field. The separation of genotypic and phenotypic responses (reciprocal transplants, common garden experiments) will remain one of the great opportunities and challenges in this field. The functional understanding of plant phenology in response to environmental signals in an evolutionary context needs to be advanced. Our current understanding of plant phenology is largely driven by what we see in terms of leaf unfolding, flowering, autumnal discoloration, and how these events correlate (statistically) with climate data. The mechanisms behind are often hidden, thus preventing theorybased projections (Körner and Basler, 2010). 
However, the methodological difficulties are overwhelming, particularly when adult trees come into play.

\section{RESEARCH PRIORITIES SHOULD BE SET BY THEORY RATHER BY TOOLS - THE NEED OF METHODOLOGICAL ADVANCES}

There are technical drivers of research priorities: the tools we have. As soon as certain aspects of plant functioning become measurable, we start using those tools and assign overarching significance to these measurements, perhaps, because we aim at doing important things, simply because we are important, at least to ourselves. Things we cannot measure or observe become a matter of unimportance. Although we will continue to depend on scientific tools and their availability, the challenge is, not to get trapped in studying what we have tools for, but to go beyond, based on the challenges posed by theory, developing novel approaches that will permit us entering the terrain that remained largely unexplored for methodological reasons.

As was explained above, water shortage and low temperature, and to some extent nutrient shortage, are not primarily affecting plant carbon capture (photosynthesis), but rather affect tissue formation directly. Well known in plant physiology, plant ecologists tend to overlook the great sensitivity of meristematic tissues to low turgor pressure, low temperature, and shortage in key nutrients. These tissues stop building new cells at water potentials, low temperatures, and critically low nutrient supply that still permit reasonably high rates of photosynthetic $\mathrm{CO}_{2}$ uptake. Not surprisingly, the initial response of plants to such tissue-level growth constraints leads to an accumulation of non-structural carbonmetabolites (osmotically inactive ones such as starch and lipids), rather than to carbon-starvation (Körner, 2003). This discrepancy between awareness and reality roots in the convenient tools and techniques we have to measure photosynthesis and the absence of tools to monitor cell division and cell differentiation in situ, and/or to assess discrepancies between demand and supply of photoassimilates.

Another example for our methods driven priorities is the generally great significance attributed to air conditioning or to climate aspects in general when manipulative experiments are designed (e.g., $\mathrm{CO}_{2}$-enrichment works), although soils exert far greater influences on plant responses to what ever treatment we apply. I invite readers to check the length authors spend on describing atmospheric conditions in their experiments versus the soil conditions. The simple reason is that we can engineer atmospheric conditions, but we have no means to engineer plant-soil or plant-soil-microbe interactions, as decisive these might be. To my knowledge, the only experiment where the response of plants to a high $\mathrm{CO}_{2}$-environment were tested with plants growing in two different soil types (see Spinnler et al., 2002), revealed two different story lines, just depending on which soil was chosen. The challenge is to arrive at a broad appreciation that soil conditions (e.g., disturbed or undisturbed) are pre-determining experimental results. I join Högberg et al. (2005) in their viewing soil microbiota associated with roots as an integral part of plant functioning, to the extent, that they may actually be seen as part of the autotrophic system, rather than belonging to the heterotrophic world.

On a similar avenue, root research was and still is a minor fraction compared to leaf research, although there is no theoretical reason for such a posteriority. Both are equally significant, in fact roots may be more influential with respect to limiting resources. The only reason is methodology. While a leaf can be studied in isolation (e.g., some sensors mounted to it), a root does not function properly without its intact rhizosphere, apart from its poor visibility. We can "bring" the atmosphere into the lab (growth chambers), but we cannot bring a coupled rhizosphere to the lab. Any pot experiment is confounded as soon as plants respond differently to two treatments, because, inevitably, the treatment changes the root-space/plant size relationship. So the challenge here is testing hypothesis on plant responses with plants grown with unconstrained, well-developed soil biota in action. Most commonly, this can only be done in the field.

\section{AS SCALES GET LARGER IN SPACE AND TIME, FEEDBACK, AND ORGANISMIC INTERACTIONS COME INTO PLAY}

Processes we have understood at one level of organization, e.g., a green leaf, are not necessarily relevant, applicable, or scaling to higher levels of organization, e.g., the whole plant or a canopy of a plant stand. Past success of plant sciences was largely founded in the reduction of complexity to smaller, highly standardized units that permit focus on a single process, replication, and repetition, all needed toward theory formation. When it comes to predict whole plant or vegetation responses, data obtained at these smaller units often do not scale. For instance, at whole plant level, it is leaf construction cost (e.g., thickness), leaf duration (thus amortization), total leaf area versus total plant mass, and/or foliage/fine root ratios that co-determine growth rate, rather than unit leaf rates of $\mathrm{CO}_{2}$ exchange (Körner, 1991). In a community context, plant traits may contribute to competitive advantage that might not even be considered significant in an isolated plant study.

The rules of scaling (e.g., by accounting for drivers such as allometry, stoichiometry, aerodynamics, or disturbance) are poorly understood, the reason why models of plant and ecosystem functioning employ "clean" mathematical base line responses for leaf functioning, but get rather vague when it comes to higher organizational level. Because we often lack the mechanistic linkages between processes at different scales, a great challenge here is to select the right/ appropriate scales of empirical work that facilitate projections to the needed larger scales, where society expects answers in the global change context. These scaling issues concern both space and time. Instantaneous responses commonly differ from long-term responses due to a multitude of physiological and allometric adjustments. As spatial scales become larger, other disciplines come into play, such as climatology, soil sciences, and population processes, with functional plant ecology inevitably becoming interdisciplinary.

Plant nutrition is a classical scaling issue. Unlike in fertilizer driven crop production or hydroponics, it is not nutrient concentration in the substrate, but nutrient release-rate from the soil that controls the amount of carbon that can be allocated to plant growth (sensu Ingestad, 1982). These nutrients are made available through plant exudates, microbes and through ion-exchange with clay-humus complexes. Stoichiometric rules define the boundaries within which plants can use photosynthates for growth in a nutrient availability context. The challenge ahead lies in exploring and defining the rules, by which 
nutrient availability and nutrient uptake control carbon uptake at whole plant or ecosystem scale.

Soils may feed back on plants at field scale with quite unexpected plant responses. For instance, most grassland responses to elevated $\mathrm{CO}_{2}$ can be explained by soil moisture savings due to stomatal responses of some (not necessarily all) species, rather than $\mathrm{CO}_{2}$ driven stimulation of photosynthesis (Volk et al., 2000; Morgan et al., 2004). The results thus depend on future moisture regimes, unlikely to be similar to the current. How would one scale growth or biodiversity responses in space and time that look like photosynthesis driven (to revisit this case again) at first glance, but at closer inspection turn out to be side effect of stomatal functioning, i.e., are water driven?

Imposing environmental, manipulations on plant communities may end up with very different responses depending on whether the community had been fully established before the treatment (e.g., steady state leaf area index and root turnover) or whether the community developed during the treatment, the latter often accelerating effects through a mix of compound interest effects on early signals when space was unconstrained and co-varying nutrient availability as space gets gradually fully occupied. Hence, the great challenge in functional plant ecology in a global change context is to allow for high complexity in experiments, making experiments large, costly, and often hard to analyze (Körner, 2006). One alternative option for some environmental drivers is to capitalize on experiments nature has "done," namely studying plant responses to environmental gradients that had acted on plants for periods much longer than any funded experimental manipulation could ever last, thus offering steady state responses, rather than initial responses to a step change in environmental conditions. On the other hand, manipulative experiments allow us to test interactive, additive impacts, which commonly cannot be differentiated in field observations. The challenge is perhaps combining the two approaches were feasible.

I highlighted these challenges imposed by research tradition, methodology, and scale issues, out of many other challenges, because they refer to particular needs of refocus. Other areas that are full of challenges are for instance plant water relations, where new, ecologically relevant paradigms of hydraulic signaling and stomatal control are emerging, new options of remote sensing of plant performance, the role of phosphorus in global plant productivity (versus the dominance of nitrogen related works), and the impact of nitrogen deposition in otherwise N-limited systems, the everlasting challenge of understanding plant-mycorrhiza interaction, and plant pathogen defense.

Whoever grafted an apple, grapes, or roses, or prepared cuttings for rooting and was surprised how such dirty "garden" surgery is tolerated without harm, might share my view that plant immunology in an ecological context represents a grand future challenge as well.

\section{ACKNOWLEDGMENTS}

I thank Wolf Frommer for talking me into this challenge, and to Erika Hiltbrunner and Günter Hoch for their comments that caused me to completely re-write an earlier draft.

\section{REFERENCES}

Farrar, J. F. (1993). Sink strength: what is it and how do we measure it? Introduction. Plant Cell Environ. 16, 1015.

Gifford, R. M., and Evans, L. T. (1981). Photosynthesis, carbon partitioning, and yield. Annu. Rev. Plant Physiol. 32, 485-509.
Högberg, P., Nordgren, A., Högberg, M. N., Ottosson-Löfvenius, M., Singh, B., Olsson, P., and Linder, S. (2005). "Fractional contributions by autotrophic and heterotrophic respiration to soilsurface CO2 efflux in boreal forests," in The Carbon Balance of Forest Biomes, eds H. Griffiths and P. G. Jarvis (Oxon, NY: Taylor \& Francis), 251-267.

Ingestad, T. (1982). Relative addition rate and external concentration driving variables used in plant nutrition research. Plant Cell Environ. 5, 443-453.

Körner, C. (1991). Some often overlooked plant characteristics as determinants of plant growth: a reconsideration. Funct. Ecol. 5, 162-173.

Körner, C. (2003). Carbon limitation in trees. J. Ecol. 91, 4-17.

Körner, C. (2006). Plant CO2 responses: an issue of definition, time and resource supply. New Phytol. 172, 393-411.

Körner, C., and Basler, D. (2010). Phenology under global warming. Science 327, 1461-1462.

Mooney, H. A. (1972). The carbon balance of plants. Annu. Rev. Ecol. Syst. 3, 315-346.

Morgan, J. A., Pataki, D. E., Körner, C, Clark, H., Del Grosso, S. J., Grünzweig, J. M., Knapp, A. K., Mosier, A. R., Newton, P. C. D., Niklaus, P. A., Nippert, J. B., Nowak, R. S., Parton, W. J., Polley, H. W., and Shaw, M. R. (2004). Water relations in grassland and desert ecosystems exposed to elevated atmospheric CO2. Oecologia 140, 11-25.

Spinnler, D., Egli, P., and Körner, C. (2002). Four-year growth dynamics of beech-spruch model ecosystems under $\mathrm{CO} 2$ enrichment on two different forest soils. Trees 16, 423-436.

Volk, M., Niklaus, P.A., and Körner, C. (2000). Soil moisture effects determine $\mathrm{CO} 2$ responses of grassland species. Oecologia 125, 380-388.

Wardlaw, I. F. (1990). Tansley review no. 27. The control of carbon partitioning in plants. New Phytol. 116, 341-381.

Received: 02 February 2011; accepted: 02 February 2011; published online: 14 February 2011.

Citation: Körner C (2011) The grand challenges in functional plant ecology. Front. Plant Sci. 2:1. doi: 10.3389/ fpls.2011.00001

This article was submitted to Frontiers in Functional Plant Ecology, a specialty of Frontiers in Plant Science.

Copyright (C) 2011 Körner. This is an open-access article subject to an exclusive license agreement between the authors and Frontiers Media SA, which permits unrestricted use, distribution, and reproduction in any medium, provided the original authors and source are credited. 